\title{
Características de carcaça e de não componentes da carcaça de cordeiros suplementados com sal forrageiro de Gliricidia sepium (Jacq.) Walq
}

\author{
[Characteristics of carcass and non-carcass components of lambs supplemented with \\ fodder salt from Gliricidia sepium (Jacq.) Walq] \\ L.G.A. Cirne ${ }^{1}$, M.R. Baroni ${ }^{2}$, G.J.C. Oliveira $^{3}$, S.M.P.L. Jaeger ${ }^{3}$, A.R. Bagaldo ${ }^{3}$, \\ M.C.P. Leite ${ }^{3}$, J.A. Marques $^{3}$, G.G.P. Carvalho ${ }^{4}$ \\ ${ }^{1}$ Aluno de pós-graduação - UNESP/FCAV - Jaboticabal, SP \\ ${ }^{2}$ Aluna de pós-graduação - Universidade Federal do Recôncavo Baiano/CCAAB - Cruz das Almas, BA \\ ${ }^{3}$ Universidade Federal do Recôncavo Baiano/CCAAB - Cruz das Almas, BA \\ ${ }^{4}$ Universidade Federal da Bahia - Salvador, BA
}

\begin{abstract}
RESUMO
O presente experimento foi conduzido com o objetivo de avaliar a porcentagem de inclusão da espécie forrageira Gliricidia sepium (Jacq.) Walq na confecção do sal forrageiro de gliricídia, por meio de características de carcaça e de não componentes da carcaça de cordeiros. Foram utilizados 30 cordeiros mestiços da raça Santa Inês, não castrados, com aproximadamente 180 dias de idade, peso vivo médio de $25 \mathrm{~kg}$, confinados, num delineamento experimental inteiramente ao acaso, com cinco tratamentos e seis repetições, em que os tratamentos foram constituídos de zero (100\% de $\mathrm{NaCl}), 93,95,97$ e $99 \%$ de inclusão de feno de gliricídia $(7,5,3$ e $1 \%$ de $\mathrm{NaCl}$ na formulação do sal forrageiro, respectivamente). A suplementação com sal forrageiro de gliricídia não afetou $(\mathrm{P}>0,05)$ o peso vivo ao abate em jejum $(28,39 \mathrm{~kg})$, peso de carcaça quente $(9,76 \mathrm{~kg})$, rendimento de carcaça quente $(34,12 \%)$, o peso de carcaça fria $(9,42 \mathrm{~kg})$, o rendimento de carcaça fria $(32,95 \%)$, as perdas de peso por resfriamento $(3,40 \%)$, assim como o peso de vísceras brancas $(2,19 \mathrm{~kg})$ e o peso de vísceras vermelhas $(1,29 \mathrm{~kg})$. Porcentagem de inclusão de até $99 \%$ de gliricídia na confecção de sal forrageiro não altera $(\mathrm{P}>0,05)$ as características de carcaça e de não componentes da carcaça de cordeiros.
\end{abstract}

Palavras-chave: carcaça, peso de abate, ovinos, suplementação

\begin{abstract}
The experiment was conducted to evaluate the inclusion of Gliricidia sepium (Jacq.) Walq forage species for the confection of the fodder salt gliricidia according to the characteristics of carcass and non-carcass components of lambs. Thirty confined, not castrated crossbred Santa Inês lambs, ageing approximately 180 days, with mean live body weight of $25 \mathrm{~kg}$, were distributed in a completely randomized design, with five treatments and six repetitions. Treatments were zero $(100 \% \mathrm{NaCl}), 93,95,97$ and 99\% inclusion of gliricidia hay $(7,5,3$ and $1 \% \mathrm{NaCl}$ in the formulation of fodder salt, respectively). The supplementation with gliricidia fodder salt did not affect $(P>0.05)$ the fasting live body weight $(28.39 \mathrm{~kg})$, hot carcass weight $(9.76 \mathrm{~kg})$, hot carcass yield $(34.12 \%)$, cold carcass weight $(9.42 \mathrm{~kg})$, cold carcass yield $(32.95 \%)$, chilling loss (3.40\%), or white $(2.19 \mathrm{~kg})$ and red viscera weight $(1.29 \mathrm{~kg})$. The inclusion of up to $99 \%$ gliricidia in the production of fodder salt did not affect $(P>0.05)$ the characteristics of carcass and noncarcass components of lambs.
\end{abstract}

Keywords: carcass, lambs, slaughter weight, supplementation

Recebido em 12 de abril de 2012

Aceito em 21 de novembro de 2012

E-mail: lgabrielcirne@hotmail.com 


\section{INTRODUÇÃO}

Considerando que a estacionalidade na produção de forragens é um dos principais fatores responsáveis pelos baixos índices de produtividade da pecuária nacional, a escolha de alimentos para reduzir esses efeitos tem relevada importância na economicidade dos sistemas e na manutenção do equilíbrio entre oferta e demanda de nutrientes (Resende et al., 2005). Sendo assim, uma busca por fontes alternativas para a suplementação animal, que potencialize ou mesmo mantenha a produção, visando à antecipação da idade ao abate e ao aumento da produção de carcaças de cordeiros, tem-se preconizado, a suplementação alimentar a pasto no período de seca do ano.

A suplementação a pasto é uma alternativa eficiente para o aumento da produção animal, pois, segundo Hodgson (1990), na maioria das situações, a forragem disponível na pastagem não contém todos os nutrientes essenciais, na proporção adequada, de forma a atender integralmente às exigências dos animais em pastejo.

O sal forrageiro, definido como uma mistura de sal mineral com feno moído de alguma(s) forrageira(s) eudicotiledônea(s), pode ser mais uma alternativa de suplementação para esses animais.

A Gliricidia sepium é uma leguminosa arbórea de porte médio, nativa no México, América Central, e no norte da América do Sul, apresenta crescimento rápido e seu enraizamento profundo lhe confere notável tolerância à seca. É considerada espécie de múltiplo uso: forragem, reflorestamento, adubação verde e cercas vivas, entre outros. É indicada como forrageira para bovinos, ovinos e caprinos, devido ao alto valor proteico apresentado na sua folhagem, variando de 20 a $30 \%$ de proteína bruta (Carvalho Filho et al., 1997).

Nesse sentido, o presente trabalho foi realizado com o objetivo de avaliar o percentual ótimo de inclusão de feno de Gliricidia sepium na confecção do sal forrageiro de gliricídia, por meio de características de carcaça e de não componentes da carcaça de cordeiros.

\section{MATERIAL E MÉTODOS}

Foram utilizados 30 cordeiros mestiços da raça Santa Inês, não castrados, com 180 dias de idade, peso vivo médio de $25 \mathrm{~kg}$, confinados, distribuídos em baias individuais de $1 \mathrm{~m}^{2}$, contendo comedouro, saleiro e bebedouro.

O experimento teve início em 07/12/09 e término em 19/02/10, sendo 14 dias de adaptação e 60 dias de período experimental, totalizando 74 dias. Antes do início do experimento, todos os animais receberam tratamento anti-helmíntico e foram vacinados contra clostridioses. Todos os tratamentos receberam feno de capim-tifton 85 (FCT-85), como suporte básico alimentar, para simular a condição de pastejo, água, sal mineral e/ou sal forrageiro de gliricídia ad libitum.

Quando da chegada ao frigorífico, todos os animais foram observados e inspecionados clinicamente. A avaliação dos animais foi realizada por meio de pesagens após serem submetidos a jejum de alimentos por um período de 14 horas, obedecendo aos procedimentos técnicos, para eliminar um importante fator da variação que é o do conteúdo gastrintestinal. No momento do abate, os animais foram insensibilizados por atordoamento na região atlanto-occipital, seguido de sangria por três minutos, pela secção da carótida e da jugular, de acordo com as normas sanitárias preconizadas pelo Serviço de Inspeção Federal (SIF). Após o abate, realizaram-se esfola, evisceração, retirada da cabeça, patas e órgãos genitais. As vísceras brancas (conjunto rúmen, retículo, omaso, abomaso, intestino delgado e grosso) e as vermelhas (coração, pulmões com a traqueia, baço e fígado) foram separadas e pesadas individualmente. Sequencialmente, as carcaças foram envolvidas por sacos plásticos identificadas por animal/tratamento $\mathrm{e}$ transportadas para câmara frigorífica a $-4^{\circ} \mathrm{C}$, onde permaneceram por 24 horas, sendo novamente pesadas para a obtenção do peso da carcaça fria.

Para obtenção das características de carcaça e de não componentes da carcaça, utilizaram-se as equações descritas a seguir: peso vivo ao abate em jejum (PVAJ = peso do animal após jejum de sólido e líquido por 14 horas), peso de carcaça quente $(\mathrm{PCQ}=$ peso da carcaça obtido logo após 
o abate), rendimento de carcaça quente $(\mathrm{RCQ}=$ (PCQ/PVAJ) x100), peso de carcaça fria (peso da carcaça após 24 horas de resfriamento em uma temperatura de $-4^{\circ} \mathrm{C}$ ), rendimento de carcaça fria $(\mathrm{RCF}=(\mathrm{PCF} / \mathrm{PVAJ}) \times 100)$, perdas de peso por resfriamento $(\mathrm{PPR}=$ [(PCQ - PCF)/PCQ] x 100), peso de vísceras brancas $(\mathrm{PVB}=$ peso do conjunto rúmen, retículo, omaso, abomaso, intestino delgado e grosso) e peso de vísceras vermelhas (PVV = peso do coração, pulmões com a traqueia, baço e fígado).

O delineamento experimental utilizado foi inteiramente ao acaso, com cinco tratamentos e seis repetições, totalizando 30 parcelas experimentais. Os tratamentos (Tab. 1) foram constituídos de zero (100\% de $\mathrm{NaCl}), 93,95,97$ e $99 \%$ de inclusão de feno de gliricídia $(7,5,3$ e $1 \%$ de $\mathrm{NaCl}$ na formulação do sal forrageiro, respectivamente).

Os dados foram analisados por meio da análise de variância e decompostos em quatro contrastes ortogonais: 1. comparação do controle vs. sal forrageiro; 2. efeito linear do nível de feno no sal; 3. efeito quadrático do nível de feno no sal; e 4. efeito cúbico do nível de feno no sal, utilizando-se o programa estatístico AgroEstat (Sistema para Análises Estatísticas de Ensaios Agronômicos, version 1.1.0.668) e adotando-se o nível de $5 \%$ de significância.

Tabela 1. Porcentagens dos ingredientes utilizados na confecção do sal forrageiro de gliricídia

\begin{tabular}{lcc}
\hline Sais forrageiros & Feno de gliricídia & $* \mathrm{NaCl}$ \\
\hline $100 \%$ de $\mathrm{NaCl}$ & - & 100,00 \\
$93 \%$ de feno de gliricídia & 93,00 & 7,00 \\
$95 \%$ de feno de gliricídia & 95,00 & 5,00 \\
$97 \%$ de feno de gliricídia & 97,00 & 3,00 \\
$99 \%$ de feno de gliricídia & 99,00 & 1,00 \\
\hline
\end{tabular}

*Níveis de garantia por kg do produto: cálcio (máx.) $174 \mathrm{~g}$, cloro $178 \mathrm{~g}$, fósforo $100 \mathrm{~g}$, sódio $117 \mathrm{~g}$, enxofre $6,2 \mathrm{~g}$, magnésio $6 \mathrm{~g}$, cobalto $150 \mathrm{mg}$, cobre $300 \mathrm{mg}$, ferro $4000 \mathrm{mg}$, iodo $110 \mathrm{mg}$, manganês $1400 \mathrm{mg}$, selênio $20 \mathrm{mg}$ e zinco $3750 \mathrm{mg}$.

A gliricídia foi obtida de ramos tenros com folhas do extrato arbóreo, que posteriormente foram desidratadas ao sol (fenadas), sobre lonas de polietileno. Com o intuito de facilitar a uniformização das misturas e evitar a seletividade pelos animais, o feno da eudicotiledônea foi moído em conjunto forrageiro, utilizando-se peneira de malha fina, antes de ser misturado ao sal mineral (Tab. 2).

Tabela 2. Composição químico-bromatológica dos alimentos utilizados nas dietas experimentais

\begin{tabular}{|c|c|c|}
\hline Item & Feno de gliricídia & Feno de tifton 85 \\
\hline MS (matéria seca) & 90,31 & 94,40 \\
\hline PB (proteína bruta) ${ }^{1}$ & 21,10 & 2,76 \\
\hline $\mathrm{EE}(\text { extrato etéreo })^{1}$ & 2,82 & 0,19 \\
\hline $\mathrm{C}(\text { cinzas })^{1}$ & 7,21 & 5,96 \\
\hline Celulose $^{1}$ & 17,07 & 35,81 \\
\hline Hemicelulose $^{1}$ & 8,90 & 31,30 \\
\hline FDN (fibra em detergente neutro) ${ }^{1}$ & 34,73 & 78,47 \\
\hline FDA (fibra em detergente ácido) ${ }^{1}$ & 25,83 & 47,17 \\
\hline Lignina $^{1}$ & 8,66 & 11,36 \\
\hline CHOT (carboidratos totais) $^{1}$ & 68,87 & 91,09 \\
\hline CNF (carboidratos não fibrosos) ${ }^{1}$ & 34,14 & 12,62 \\
\hline
\end{tabular}
${ }^{1}$ em $\%$ da MS.

\section{RESULTADOS E DISCUSSÃO}

Não houve diferença significativa $(\mathrm{P}>0,05)$ nas características de carcaça de cordeiros suplementados com sal forrageiro de gliricídia
(Tab. 3), não sendo possível ajustar um modelo (P>0,05) para explicar o comportamento das variáveis em função das porcentagens de inclusão de gliricídia na confecção do sal forrageiro. 
Tabela 3. Peso vivo ao abate em jejum (PVAJ), peso de carcaça quente (PCQ), rendimento de carcaça quente (RCQ), peso de carcaça fria (PCF), rendimento de carcaça fria (RCF) e perdas de peso por resfriamento (PPR) de cordeiros suplementados com sal forrageiro, em função dos tratamentos

\begin{tabular}{|c|c|c|c|c|c|c|c|c|c|c|}
\hline \multirow{2}{*}{ Item } & \multicolumn{5}{|c|}{ Porcentagem de gliricídia } & \multirow{2}{*}{$\begin{array}{l}\mathrm{Na} v s \text {. } \\
\text { gliricídia }\end{array}$} & \multicolumn{3}{|c|}{ Valor de $\mathrm{P}$} & \multirow{2}{*}{$\mathrm{CV}(\%)$} \\
\hline & 0 & 93 & 95 & 97 & 99 & & $\mathrm{~L}$ & $\mathrm{Q}$ & $\mathrm{C}$ & \\
\hline PVAJ (kg) & 27,50 & 27,75 & 27,80 & 29,50 & 29,40 & $\mathrm{~ns}$ & ns & ns & ns & 12,96 \\
\hline PCQ (kg) & 8,95 & 9,70 & 9,70 & 9,77 & 9,88 & ns & ns & ns & ns & 15,37 \\
\hline $\operatorname{RCQ}(\%)$ & 32,45 & 34,98 & 34,69 & 33,16 & 33,66 & ns & ns & ns & ns & 6,94 \\
\hline $\mathrm{PCF}(\mathrm{kg})$ & 8,57 & 9,32 & 9,38 & 9,40 & 9,60 & ns & ns & ns & ns & 14,96 \\
\hline $\mathrm{RCF}(\%)$ & 31,10 & 33,60 & 33,58 & 31,90 & 32,73 & ns & ns & ns & ns & 6,50 \\
\hline $\operatorname{PPR}(\%)$ & 4,09 & 3,90 & 3,13 & 3,80 & 2,77 & ns & ns & ns & ns & 31,98 \\
\hline
\end{tabular}

O peso vivo ao abate em jejum médio, de $28,39 \mathrm{~kg}$, foi semelhante aos obtidos por Gonçalves (2007), de 28,15; 26,22 e 27,17kg, em cordeiros mestiços da raça Santa Inês, suplementados com sal forrageiro de leucena (SFL), parte aérea de mandioca (SFPAM) e feijão-bravo (SFFB), respectivamente; e por Dantas et al. (2008), de 27,09kg, em cordeiros da raça Santa Inês, suplementados com $1,5 \%$ do peso vivo (PV) de concentrado, em pastagem de capim-buffel (Cenchrus ciliaris). Da mesma forma, o peso de carcaça quente médio, de $9,76 \mathrm{~kg}$, foi similar aos observados por Gonçalves (2007), de 10,40; 9,64 e 9,33kg, em cordeiros suplementados com SFL, SFPAM e SFFB, respectivamente; e por Dantas et al. (2008), de $9,55 \mathrm{~kg}$, em cordeiros recebendo $1,0 \%$ do PV de concentrado, o que sugere que a espécie forrageira Gliricidia sepium seja uma alternativa na confecção de sal forrageiro para suplementação de ovinos no período da seca.

O rendimento de carcaça quente (RCQ), de $34,12 \%$ (Tab. 3), foi inferior aos encontrados por Carvalho et al. (2006), de 41,52\%, em cordeiros mestiços da raça Texel, suplementados com $1,0 \%$ do PV de concentrado, em pastagem de capim-tifton 85. Contudo, o resultado de RCQ desta pesquisa foi próximo ao apresentado por Gonçalves (2007), que registrou valores médios de 36,$73 ; 34,36$ e $36,80 \%$, respectivamente, em ovinos provenientes da raça Santa Inês suplementados com SFL, SFPAM e SFFB. Os resultados obtidos, neste ensaio, para o RCQ podem ser considerados satisfatórios, pois a média está na faixa proposta por Osório (1992), a qual varia entre 30,40 e $60,80 \%$.

O valor concernente ao rendimento de carcaça fria (RCF), de 32,95\% (Tab. 3), foi inferior aos obtidos por Dantas et al. (2008), de 36,68 e $40,25 \%$, para os animais suplementados com 1,0 e $1,5 \%$ do PV de concentrado, respectivamente. Possivelmente o menor RCF encontrado, neste estudo, seja devido à dieta que possibilitou ganho de peso moderado.

Não foram observadas diferenças $(\mathrm{P}>0,05)$ nas perdas de peso por resfriamento em função das porcentagens de gliricídia utilizadas na confecção do SFG, com valor médio de 3,40\% (Tab. 3), resultado semelhante aos relatados por Dantas et al. (2008), de 3,33\%. Os valores de perdas de peso por resfriamento para ovinos de raças de corte são aceitáveis quando estão entre 3 e 4\% (Sañudo et al., 1981).

O peso de vísceras brancas e vermelhas de cordeiros em confinamento não foi afetado ( $\mathrm{P}>0,05)$ pela suplementação com sal forrageiro de gliricídia (Tab. 4).

Tabela 4. Peso de vísceras brancas (PVB) e peso de vísceras vermelhas (PVV) de cordeiros suplementados com sal forrageiro, em função dos tratamentos

\begin{tabular}{|c|c|c|c|c|c|c|c|c|c|c|}
\hline \multirow{2}{*}{ Item } & \multicolumn{5}{|c|}{ Porcentagem de gliricídia } & \multirow{2}{*}{$\begin{array}{l}\text { Na } v s . \\
\text { gliricídia }\end{array}$} & \multicolumn{3}{|c|}{ Valor de $\mathrm{P}$} & \multirow{2}{*}{$\mathrm{CV}(\%)$} \\
\hline & 0 & 93 & 95 & 97 & 99 & & $\mathrm{~L}$ & $\mathrm{Q}$ & $\mathrm{C}$ & \\
\hline PVB (kg) & 2,13 & 2,10 & 2,20 & 2,16 & 2,29 & ns & ns & ns & ns & 11,59 \\
\hline PVV (kg) & 0,95 & 1,00 & 1,02 & 0,99 & 1,07 & ns & ns & ns & ns & 13,18 \\
\hline
\end{tabular}


O PVB médio encontrado, de $2,19 \mathrm{~kg}$, foi semelhante ao obtido por Honório (2003), de $2,01 \mathrm{~kg}$, em borregos da raça Santa Inês, e superior ao registrado por Maior Júnior (2008), de $1,52 \mathrm{~kg}$, em cordeiros sem padrão racial definido (SPRD). Provavelmente, o menor valor encontrado por Maior Júnior (2008) tenha sido pelo fato de ter avaliado animais SPRD que geralmente apresentam baixo desempenho produtivo, o que pode resultar em menor PVB.

O PVV observado neste estudo, de $1,29 \mathrm{~kg}$, foi inferior aos encontrados por Carvalho et al. (2007), de $1,61 \mathrm{~kg}$, em cordeiros da raça Texel, sendo importante ressaltar a composição genética dessa raça, pois raças especializadas na produção de carne, como a Texel, apresentam elevadas taxas de ganhos de peso, o que possivelmente irá refletir no peso dos não componentes da carcaça.

\section{CONCLUSÕES}

Sal forrageiro formulado com até $99 \%$ de gliricídia em dietas para cordeiros em confinamento não altera as características de carcaça e dos não componentes da carcaça.

\section{REFERÊNCIAS}

CARVALHO FILHO, O.M.; DRUMOND, M.A.; LANGUIDEY, P.H. Gliricidia sepium leguminosa promissora para regiões semiáridas. Petrolina, PE: EMBRAPA-CPATSA, 1997. 16p. (Circular Técnica, 35).

CARVALHO, S.; BROCHIER, M.A.; PIVATO, J. et al. Ganho de peso, características da carcaça e componentes não-carcaça de cordeiros da raça Texel terminados em diferentes sistemas alimentares. Cienc. Rur., v.37, p.821-827, 2007.

CARVALHO, S.; VERGUEIRO, A.; KIELING, R. et al. Desempenho e características da carcaça de cordeiros mantidos em pastagem de tifton-85 e suplementados com diferentes níveis de concentrado. Rev. Bras. Agroci., v.12, p.357$361,2006$.

DANTAS, A.F.; PEREIRA FILHO, J.M.; SILVA, A.M.A. et al. Características da carcaça de ovinos Santa Inês terminados em pastejo e submetidos a diferentes níveis de suplementação. Cienc. Agrotec., v.32, p.1280-1286, 2008.
GONÇALVES, G.S. Sal forrageiro de espécies vegetais xerófitas para cordeiros. 2007. 59f. Dissertação (Mestrado em Ciências Agrárias) Escola de Agronomia, Universidade Federal da Bahia, Cruz das Almas, 2007.

HODGSON. J. (Ed). Grazing management: science into practice. Harlow: Longman, 1990. 203p.

HONÓRIO, A.F. Utilização do farelo de girassol em rações completas para borregos da raça Santa Inês nas fases de recria e terminação. 2003. Monografia (Graduação em Zootecnia). Centro de Ciências Agrárias, Universidade Federal da Paraíba, Areia, 2003.

MAIOR JÚNIOR, R.J.S.; CARVALHO, F.F.R.; BATISTA, A.M.V. et al. Rendimento e características dos componentes não-carcaça de ovinos alimentados com rações baseadas em cana-de-açúcar e ureia. Rev. Bras. Saúde Prod. Anim., v.9, p.507-515, 2008.

OSÓRIO, J.C.S. Estudio de la calidad de canales comercializadas en el tipo ternasco segun la procedencia: bases para la mejora de dicha calidad en Brasil. 1992. 335f. Tese (Doutorado em Produção Animal) Universidade de Zaragoza, Zaragoza, 1992.

RESENDE, F.D.; SIGNORETTI, R.D.; COAN, R.M. et al. Terminação de bovinos de corte com ênfase na utilização de volumosos conservados. In: REIS, R.A.; SIQUEIRA, G.R.; BERTIPAGLIA, L.M.A. et al. (Ed). Volumosos na produção de ruminantes. Jaboticabal: FUNEP, 2005. p.83106.

SAÑUDO, C.; PIEDRAFITA, J.; SIERRA, I. Estudio de la calidad de la canal y de la carne en animales cruzados Romanov por Rasa Aragonesa. 2. Comparación en el tipo comercial ternasco com Rasa en pureza. In: JORNADAS CIENTÍFICAS DE LA SOCIEDAD ESPAÑOLA DE OVINOTECNIA, 7., 1981, Talavera de la Reina. Espanha. Actas... Talavera de la Reina: [s.n.] 1981. p.483-489. 